\title{
REVITALISASI PARADIGMA KONSERVATIF PENDIDIKAN DEMOKRASI PADA PENDIDIKAN KEWARGANEGARAAN DENGAN INOVASI MEDIA PEMBELAJARAN
}

\author{
Abdinur Batubara, Cecep Darmawan \\ Program Studi Magister Pendidikan Kewarganegaraan \\ Universitas Pendidikan Indonesia Jl. Setiabudi No.229 Bandung \\ email:abdinurbb04@student.upi.edu
}

\begin{abstract}
This article aimed to describe the conservative paradigm revitalization of democratic learning on civic education ( $\mathrm{PKn}$ ) direction using the Innovation of Digital Democracy Learning Media (IMPDD). The process using quantitative descriptive approach to the design of classroom action research. Data collection tools using techniques of observation and questionnaires. The study population is a class XI student of SMAN 1 Medan with samples of class XI-MIA 7. Results showed 99.3\% of students (respondents) responded strongly agree on IMPDD. While teachers tutor (Respondent) gave a very good score at the interval IMPDD. Thus it can be a factor IMPDD imperative to build an effective learning paradigm Civics in school.
\end{abstract}

Keywords: revitalization, democracy, citizenship education, learning media innovation.

\begin{abstract}
Abstrak: Kajian ini bertujuan mendeskripsikan revitalisasi paradigma konservatif pembelajaran demokrasi pada pendidikan kewarganegaraan (PKn) ke arah yang Innovatifdengan menggunakan Inovasi Media Pembelajaran Demokrasi Digital (IMPDD). Proses yang ada menggunakan pendekatan deskriptif kuantitatif dengan desain penelitian tindakan kelas. Alat pengumpulan data menggunakan tehnik observasi dan angket. Populasi penelitian adalah siswa kelas XI SMA N 1 Medan dengan sampel kelas XI-MIA 7. Hasil kajian menunjukkan bahwa 99,3\% siswa (responden) merespon sangat setuju pada IMPDD. Sedangkan guru pamong (responden) memberi skor sangat baik pada interval keberhasilan IMPDD. Dengan demikian maka IMPDD dapat menjadi faktor imperative untuk membangun paradigma pembelajaran PKn yang efektif di sekolah.
\end{abstract}

Kata Kunci: revitalisasi, demokrasi, pendidikan kewarganegaraan, inovasi media pembelajaran.

Transformasi peradaban dunia telah memasuki era Teknologi Informasi dan Komunikasi (TIK), dimana manusia ditandai dengan fenomena masyarakat teknologi. Hal ini sejalan dengan pendapat Naisbitt dalam Wahab dan Sapriya (2011:205) yang menyatakan bahwa "pada abad XXI di era baru ini ditandai oleh fenomena Futuris (sebutan masyarakat teknologi) dimana Naisbitt menyebut era dengan fenomena masyarakat Global Paradox dan Information Society/Post-Civilize (masyarakat informasi)". Era Post-civilize sendiri ditandai dengan adanya tantangan dalam dimensi politik yaitu manusia demokrasi. Tantangan tersebut menandakan dibutuhkannya manusia demokrasi antisipator sebagai perlawanan terhadap masayarakat pasif dan parokial yang semakin merambat luas dan semakin mengkhawatirkan akan terjadinya penurunan kualitas dan tujuan dari demokrasi itu sendiri.

Tantangan demokrasi merupakan persoalan yang mutlak harus di hadapi dengan bijak. Untuk itu, kekhawatiran akan kepasifan dan budaya parokial warga harus di tindaki dengan cara yang bijak demi terwujudnya Civic Culture (Budaya Kewarganegaraan) Indonesia yang demokratis dan berakar dari pancasila. Salah satu cara yang paling bijaksana adalah melalui pendidikan atau lebih tepatnya adalah pendidikan demokrasi yang efektif dan dinamis. Dalam hal ini Pendidikan Kewarganegaraan (PKn) lah yang mengemban tugas utama sebagai wahana pendidikan demokrasi di Indonesia. sebagaimana dalam Winataputra (2015 : 282) bahwa “PKn 
mengembang misi multidimensional atau multidmensional citizenship yang mana PKn memiliki misi membangun budaya kewarganegaraan sebagai salah satu determinan kehidupan yang demokratis berdasarkan pancasila (misi sosiokultural)". Namun yang menjadi persoalan utamanya adalah sudah sejauh mana pendidikan demokrasi itu di implikasi dengan baik oleh seluruh pemangku kepentingan khususnya oleh sang wahana-Nya yaitu PKn.

Paradigmanya adalah pertama, pembelajaran demokrasi PKn masih Un-Innovatif sehingga tidak dinamis dan proporsional. Proses pembelajaran PKn yang seharusnya lebih mengembangkan kompetensi civicdisposition dan civic skill, dalam praktiknya lebih mengembangkan civic intellegence yang ditandai sistem pembelajaran konvensional. Sehingga, PKn tidak diarahkan untuk memanusiakan manusia secara utuh, lahir dan batin, tetapi lebih diorientasikan pada hal-hal yang bersifat kognitif yang kering dari sentuhan nilainilai moral, kemanusiaan, religi, dan budi pekerti. Sebagaimana menurut Soemantri (2001: 245) bahwa : "kurang bermaknanya PKn bagi peserta didik dikarenakan masih dominannya penerapan metode pembelajaran konvensional seperti ground covering technique, indoktrinasi, dan narrative technique dalam pembelajaran PKn sehari-hari”.

Kedua, pendidikan demokrasi oleh PKn masih belum mengarah pada sasaran pendidikan civic participatory (partisipasi warganegara) yang demokratis. Sudah seharusnya PKn mengarah pada komponen civic participatory, sebagaimana dijelaskan dalam Setiawan (2014:141) bahwa:"PKn sudah harus mengarah pada pembinaan desirable personal qualities (kualitas pribadi yang diinginkan) seperti dalam hal ini atau dalam konteks demokrasi dimana pembinaan pada perasaan dan kemauan memiliki kompetensi civic partisipatory (partisipasi warganegara) serta berbudaya civic culture (budaya kewarganegaraan)".

Ketiga, Pkn masih belum menunjukkan secara signifikan sebagai wahana pendidikan demokrasi. Padahal PKn dipercaya sebagai wahananya pendidikan demokrasi di Inodnesia. Sebagaimana dirangkum oleh Winataputra (2015:180) bahwa "prospek pendidikan kewarganegaraan sebagai domain kurikuler dapat kita lihat dalam konstelasi pemikiran yang terdapat dalam UU RI No 20 tahun 2003 tentang Sistem Pendidikan Nasional (UU Sisdiknas). Dalam UU Sisdiknas tersebut upaya sistemik untuk membangun warganegara yang cerdas, demokratis, dan bertanggung jawab diwadahi oleh substansi kajian PKn dan IPS mempunyai kedudukan dan fungsi interaktif”.

Ketiga hal tersebut menandakan adanya paradigma konservatif yang harus diperbaiki. Ravitalisasi adalah strategi bijak untuk menjawab persoalan kekhawatiran faktor signifikan PKn sebagai wahana pendidikan demokrasi. Pembelajaran yang innovatif, kritis, dinamis, dan menarik tentunya dibutuhkan dalam PKn. Untuk mendukung transformasi zaman serta kebutuhan kurikuler PKn maka salah satu faktor terpenting pembelajaran demokrasi dalam PKn adalah media pembelajarannya.

Media yang innovatif, menarik, mendukung penuh kebutuhan kurikuler PKn sebagai pendidikan demokrasi yaitu membangun warganegara yang cerdas; demokratis; dan bertanggung jawab,serta media yang dapat membangun desirable personal qualities siswa demi terwujudnya komponen civic partisipatory. Untuk menghadapi masalah paradigma konservatif pembelajaran demokrasi pada PKn yang berakibatkan kepasifan warga dan budaya parokial warga pada demokrasi. Maka dalam penelitian ini, peneliti bermaksud untuk membuat sebuah media pembelajaran pendidikan demokrasi pada PKn untuk menjembatani permasalahan tersebut. Media pembelajaran ini akan diimplikasi pada siswa di sekolah. Adapun media yang dimaksud dinamakan Inovasi Media Pembelajaran Pendidikan Demokrasi Digital (IMPDD).

Upaya meningkatkan efektivitas rencana media pembelajaran terebut maka peneliti juga akan melakukan treatment tindakan kelas demi memberi faktor signifikan pada pembelajaran PKn serta mendukung faktor teknologi. Sebagaimana yang dijelaskan oleh Sanjaya (2011:34-35) bahwa: "PTK memiliki manfaat yang sangat besar buat guru untuk mneingkatkan kualitas pembelajaran, perbaikan dan peningkatan kerja, keberhasilan PTK dapat berpengaruh pada guru lain, PTK dapat mendorong guru menjadi profesional, serta yang lebih penting adalah PTK akan membuat guru akan selalu mengikuti kemajuan Ilmu Pengetahuan dan Teknologi (PTK)”. 


\section{METODE}

Kajian ini didasari penelitian yang menggunakan pendekatan deskriptif kuantitatif dengan desain penelitian tindakan (action reasearch). Desain penelitian ini digunakan sebagai upaya untuk merekonstruksi sesuatu dengan pemahaman logis yang bersifat terbuka dan akumulatif. Kemudian model yang digunakan adalah model Classroom Actions Research, dipilih karena mendukung pada fokus terapan yaitu IMPDD (Inovasi Media Pembelajaran Demokrasi Digital) dan juga mendukung usaha peneliti untuk memperbaiki aspek kompetensi baik guru dan khususnya peserta didik dalam pembelajaran pendidikan demokrasi. Sehubungan dengan itu Creswell (2015:1180) menjelaskan bahwa:"Action Reasearch (peneitian tindakan) memiliki fokus terapan. Penelitian tindakan adalah prosedur sistematis yang dilakukan oleh guru (atau individu lainnya dalam ranah pendidikan) untuk mengumpulkan informasi dan setelah itu memperbaiki cara kerja ranah pendidikan mereka, pengajaran mereka, dan pembelajaran siswa mereka”.

Jadi kajian yang ada menggunakan desain penelitian tindakan dengan model penelitian tindakan kelas dan menjadikan IMPDD sebagai terapan perbaikan pembelajaran dan usaha untuk membangun kembali (Revitalisasi) pembelajaran demokrasi di era Post-Civilize serta memperbaiki aspek Civic Culture-nya peserta didik dalam konteks pendidikan demokrasi disekolah.

\section{HASIL DAN PEMBAHASAN}

Berbagai modifikasi yang dilakukan selama 3 (tiga) siklus pembelajaran dengan menambah fitur dan perbaikan pada IMPDD, beberapa kekurangan pada siklus dapat diperbaiki. Kemudian dengan treatment dan semua keunggulan dari IMPDD memberi pengaruh signifikan pada peserta didik kelas XI MIA-7 SMA $\mathrm{N} 1$ Medan. Beberapa pengaruh yang mengindikasikan dapat merevitalisasi paradigma pembelajaran demokrasi PKn sebagai berikut.

a. Pemahaman akan civic culture anak didik lebih luas dan bukan hanya dalam konteks pemerintahan saja namun juga dalam konteks demokrasi di lingkungan sekolah.

b. Treatment pada fitur persistensi tentunya memberi efek pembelajaran PKn lebih inovatif dan menyenangkan. Selain itu fitur ini aspek kognitif siswa yaitu kepercayaan pada diri untuk bersumbangsi pada kehidupan yang demokratis. Persistensi sendiri tentunya adalah salah satu teori pembelajaran dalam kognitif sosial yaitu model Self Effication (Efikasi Diri). Menurut Bandura dalam Trujillo dan Trunner dalam jurnal Life Science Education (2014 : 7) : "Self-efficacy is an aspect of social cognitive theory defined as "the exercise of human agency through people's beliefs in their capabilities to produce desired effects by their actions".

c. Membaca berita dan menganalisisnya adalah bagian dari perkembangan kognitif anak. Ini menjadi bagian dari perkembangan cara belajar anak. Menurut Bloom dalam jurnal Life Science Education (2008 : 373) : "Bloom's is a well-defined and broadly accepted tool for categorizing types of thinking into six different levels: knowledge, comprehension, application, analysis, synthesis, and evaluation". Blooms mendefinisikan tingkat kognitif menjadi enam yang salah satunya adalah analisis. Selanjutanya bloom menjelaskan beberapa indikator menganalisis "(1) Analyze and interpret data in primary literature or a textbook without reading the author's interpretation and then compare the authors' interpretation with your own (2) Analyze a situation and then identify the assumptions and principles of the argument (3) Compare and contrast two ideas or concepts (4) Create a map of the main concepts by defining the relationships of the concepts using oneor two-way arrows". Dari keempat indikator tersebut IMPDD memfasilitasi fitur analisis siswa pada berita seputar demokrasi melalui online.

d. Sebanyak $99,3 \%$ guru pamong meyakini IMPDD memberi efek sangat baik pada :

1) Antusisme anak mengikuti pembelajaran demokrasi oleh guru;

2) IMPDD memiliki kapabilitas yang sangat baik sebagai media wahana pendidikan demokrasi;

3) Fitur IMPDD mendukung perkembangan aspek kognitif anak (dalam hal ini self effication);

4) Cara belajar anak sangat variatif, dengan kolaborasi antara guru dan siswa;

e. Siswa sangat meyakini bahwa IMPDD memberi dampak signifikan pada : 
1) Kompetensi desirable personal mereka.

2) Merasa sangat antusias mengikuti pembelajaran;

3) Sangat tertarik dan termotivasi untuk menganalisis terutama pada fitur baca berita;

4) Siswa merasa sangat tertarik juga dengan animasi-animasi yang tersedia pada IMPDD sehingga pembelajaran menjadi tidak membosankan.

\section{SIMPULAN}

Revitalisasi paradigma konservatif pendidikan demokrasi PKn dapat dijembatani dengan treatment inovasi media pembelajaran atau dalam hal ini adalah IMPDD. Indikator keberhasilan telah tercapai terlebih hanya pada siklus I, siklus II hanyalah perbaikan dan penyempurnaan dari siklus I. Peran terbesar IMPDD dalam mengubah paradigma konservatif pendidikan demokrasi PKn adalah fiturnya yang menarik, kebulatan materi, sistematika desain

\section{DAFTAR RUJUKAN}

Creswell, J, W. 2015. Penelitian Kualitatif \& Desain Riset. Yogyakarta : Pustaka Pelajar.

Sanjaya, W. 2011. Perencanaan Dan Desain Sistem Pembelajaran. Jakarta : PT Kencana.

Setiawan, D. 2014. Kapita Selekta Kewarganegaraan. Medan : Cahaya Ilmu Press.

Somantri, M.N. 2001. Menggagas Pembaharuan Pendidikan IPS. Bandung: PT. Remaja Rosda Karya. media yang sistematis, serta ketegasan materi demokrasi yang baik pada IMPDD. Salin itu unsur visualitas sangat berperan dalam IMPDD. Dan pembelajaran demokrasi PKn menjadi lebih variatif, menarik dan kritis. Hal ini terlihat dengan 99,3\% guru pamong setuju kalau IMPDD memberi efek yang sangat baik terhadap pembelajaran demokrasi pada PKn. Dan respon siswa terhadap pembelajaran demokrasi melalui IMPDD juga sangat baik.

IMPDD berhasil menjadi revitalitator paradigma konservatif pendidikan demokrasi PKn yang masih un-innovatif, kurang menarik, domain kurikuler nya kurang jelas, dan cara belajarnya yang kurang efektif menjadi innovatif, variatif, kritis, dan menyenangkan sehingga menciptakan suasana pembelajaran PKn yang kritis dalam konteks demokrasi, menarik untuk dipahami, dan pembelajaran demokrasi tidak lagi membosankan karena fitur bernyanyi pada IMPDD yang membuat suasana belajar menjadi menyenangkan namun tidak lepas dari fokus dan kritis.

Wahab, A.A, dan Sapriya. 2011. Teori dan Landasan Pendidikan Kewarganegaraan. UPI : Press SPs UPI.

Winataputra, U.S. 2015. Pendidikan Kewarganegaraan : Refleksi HistorisEpistimologis dan Rekonstruksi Untuk Masa Depan. Banten : Universitas Terbuka.

Trujillo, G \& Tanner, K.D. 2014. Considering the Role of Affect in Learning : Monitoring Students' Self-Efficacy, Sense of Belonging, and Science Identity. CBE-Life Sciences Education Vol. 13, 6-15, Spring 2014. doi: $10.1187 /$ cbe.13-12-0241. 